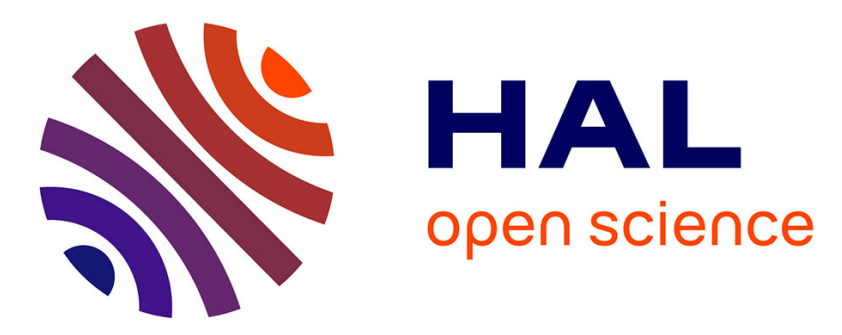

\title{
Equilibrium structure and energetics of CHNO isomers: Steps towards ab initio rovibrational spectra of quasi-linear molecules
}

\author{
M. Mladenovic, Marius Lewerenz
}

\section{- To cite this version:}

M. Mladenovic, Marius Lewerenz. Equilibrium structure and energetics of CHNO isomers: Steps towards ab initio rovibrational spectra of quasi-linear molecules. Chemical Physics, 2008, 343 (2-3), pp.129. 10.1016/j.chemphys.2007.06.033 . hal-00750855

\section{HAL Id: hal-00750855 https://hal.science/hal-00750855}

Submitted on 12 Nov 2012

HAL is a multi-disciplinary open access archive for the deposit and dissemination of scientific research documents, whether they are published or not. The documents may come from teaching and research institutions in France or abroad, or from public or private research centers.
L'archive ouverte pluridisciplinaire HAL, est destinée au dépôt et à la diffusion de documents scientifiques de niveau recherche, publiés ou non, émanant des établissements d'enseignement et de recherche français ou étrangers, des laboratoires publics ou privés. 


\title{
Equilibrium structure and energetics of CHNO isomers: steps towards ab initio rovibrational spectra of quasi-linear molecules
}

\author{
Mirjana Mladenović* and Marius Lewerenz ${ }^{\dagger}$ \\ Laboratoire de Chimie Théorique, Bâtiment Lavoisier, \\ Université Paris Est, Marne la Vallée, 5 boulevard Descartes, \\ Champs sur Marne, 77454 Marne la Vallée Cedex 2, France
}

\begin{abstract}
We report large-scale electronic structure calculations for fulminic acid, HCNO, isocyanic acid, $\mathrm{HNCO}$, and cyanic acid, HOCN, in their ground electronic states. The coupled cluster CCSD(T) method including all single and double excitations and a perturbative term for connected triple substitutions is used in conjunction with large correlation consistent polarized valence basis sets of the form cc-pVXZ $(\mathrm{X}=2-6)$ and cc-pCVXZ $(\mathrm{X}=2-5)$. Our results show the importance of including all electrons in the correlation treatment to obtain a converged molecular structure for the extremely floppy HCNO molecule and the correct energetics of the three isomers. All electron correlation calculations and frozen core calculations with very large basis sets clearly converge towards a linear electronic minimum for HCNO surrounded by a very large flat region of the potential energy surface for hydrogen bending motions. For each of the three isomers we have computed the barrier to linearity along the respective minimum energy path and several spectroscopic parameters and equilibrium rotational constants.
\end{abstract}

Keywords: Ab initio calculation; CHNO; Equilibrium structure; Quasi-linear molecules; Potential energy surface

\section{INTRODUCTION}

Molecules with a non-linear electronic minimum but a low barrier to linearity allowing a large amplitude bending motion may exhibit rovibrational spectra with level patterns reminiscent of molecules with a rigid linear skeleton and are usually referred to as quasi-linear molecules. ${ }^{1-3}$ The large amplitude bend contributes a vibrational angular momentum which couples with the overall rotational angular momentum. Furthermore the bending motion is frequently coupled with the highfrequency stretch modes. The combination of these features leads to particularly complicated rovibrational spectra, exhibiting many fascinating features, such as Fermi and $l$-type resonances, Coriolis coupling, and large centrifugal distortion.

Fulminic acid, HCNO, is one of the most important representatives of this class of molecules and has been subjected to extensive previous experimental ${ }^{2,4-9}$ and theoretical ${ }^{10-16}$ analyses. Winnewisser and Winnewisser ${ }^{4}$ were the first to propose in 1971 a quasilinear molecular model for the fulminic acid molecule. An unreasonably short $r_{s}(\mathrm{HC})$ distance of $1.0266 \AA$ was initially derived from the microwave data within a linear molecule model for HCNO. ${ }^{4}$ A deviation from Bernstein's rule ${ }^{17}$ for $\mathrm{CH}$ stretching fundamentals motivated Winnewisser et al. to suggest a non-linear equilibrium structure, possessing an $\mathrm{HCN}$ angle of ca. $162^{\circ}$. The classification of quasi-linear molecules proposed in Ref. 6 places HCNO rather close to the linear molecule limit. A semirigid bender study of Bunker et al. ${ }^{10}$ led to the conclusion that HCNO has a linear equilibrium structure and bent vibrationally averaged structures. A small barrier to linearity of $11.5 \mathrm{~cm}^{-1}$ was determined for the effective ground-state potential energy profile along the HCN angle. Such a structure was actually called quasi-bent in Ref. 10.

The electronic structure problem of HCNO has turned out to be particularly hard, leading to strongly basis set and correlation method dependent results, such that the equilibrium geometry and the size of the barrier to linearity, if there is any, are still unclear. Whereas MP2, MP4, and MCSCF calculations favour a nonlinear structure, a linear equilibrium was found at the SCF, MP3, CISD, and CCSD levels of theory, ${ }^{11,14}$ and also with CCSD $(\mathrm{T}) / \mathrm{TZ2P} .{ }^{12}$ Koput et al. ${ }^{14}$ deduced a small barrier to linearity of $7 \mathrm{~cm}^{-1}$ by means of $\operatorname{CCSD}(\mathrm{T}) / \mathrm{cc}-$ pVQZ. Several $a b$ initio studies have additionally reported harmonic vibrational frequencies and/or energetics for the system [H,C,N,O]. ${ }^{13,15,16,18}$ So far, there is, however, only a single study providing variational results for rovibrational states of HCNO. In that study, Pinnavaia et al. ${ }^{13}$ developed and employed a six-dimensional MP2/DZP potential enery surface, on which the optimized bent HCNO configuration is ca. $330 \mathrm{~cm}^{-1}$ more stable than the optimized linear configuration.

High-quality rovibrational calculations are the ultimate means to clarify the characteristic rovibrational spectral patterns by theoretical means. The starting point for such calculations is an accurate potential energy surface (PES), which samples large portions of the available configuration space, covering at least those degrees of freedom which are essential for understanding the internal molecular dynamics. The quasi-linear species 
HXYZ with a hydrogen atom attached to a (nearly linear) chain of heavy atoms pose a very demanding computational task from both the electronic structure and rovibrational point of view because of the strongly anharmonic large amplitude HXY bending vibration.

With the ultimate goal to develop a full-dimensional potential energy surface for the fulminic acid molecule in its electronic ground state, our initial purpose was to study the equilibrium structure with a high level of accuracy and to identify the best trade-off between accuracy and expense of computer time. However, our calculations beyond the frozen-core approximation showed a prominent contribution of core correlation at the equilibrium internuclear geometry of HCNO. Since this quantity is relevant for the calculation of energetics of the [H,C,N,O] system, we have extended our work to include $\mathrm{HNCO}$ and HOCN, too.

Isocyanic acid, HNCO, is the most stable among all CHNO isomers. ${ }^{19}$ It is energetically followed by cyanic acid, HOCN, and fulminic acid, HCNO. From the historical point of view, the isomers are important because of the first experimental evidence of isomerism in 1826, when Liebig and Wöhler agreed that HNCO and HCNO possess the same chemical composition, but are structurally distinct. ${ }^{20}$ The CHNO isomers (most prominently HNCO) are expected to participate in interstellar chemistry and to play a major role in the RAPRENO ${ }_{x}$ process for NO reduction in combustion. ${ }^{18,21-23} \mathrm{HNCO}$ is considered also to be quasi-linear, exhibiting a barrier to linearity of $1899 \mathrm{~cm}^{-1}$ according to a semirigid bender analysis of Niedenhoff et al. ${ }^{24}$ Whereas both HCNO and $\mathrm{HNCO}$ possess very rich rovibrational spectra in the gas phase, ${ }^{2,4-9}$ HOCN could be studied solely under matrix conditions. ${ }^{20,25}$ For HNCO and HOCN, Pinnavaia et al. reported only perturbational results. ${ }^{13}$ We refer to Refs.13,14,16 for an overview of the previous experimental and theoretical work on the CHNO isomers.

Energy levels associated with a large amplitude bending vibration may develop a pattern typical for linear molecules, even for a bent equilibrium structure. ${ }^{1,26}$ This was found in our recent study ${ }^{27}$ on cyanocarbene, HCCN. In spite of a nonlinear equilibrium structure, characterized by $\angle(\mathrm{HCC})_{e}$ of $147^{\circ}$ and $\angle(\mathrm{CCN})_{e}$ of $175^{\circ}$ for a MR-ACPF PES, the rovibrational energy levels of the radical were easily assigned following the conventional linear molecule notation. This phenomenon hinges on the barrier to linearity, determined to be $287 \mathrm{~cm}^{-1}$ for HCCN. Numerically exact rovibrational states of HCCN were calculated for $J=0-4$, using the method described in Ref. 28. This type of treatment is the next logical step of our HCNO project.

In the present work, extensive $a b$ initio calculations of the electronic ground state with coupled cluster techniques and large basis sets have been performed for each of the three isomers studied. Two families of basis sets were employed to approach the one-particle basis-set limit, including valence and all-electron correlation (Section II). The geometries of the minima have been opti- mized via numerical gradient techniques (Section III A). The barriers to linearity and isomerization energies have been derived (Section IIIB). The harmonic vibrational frequencies have been computed in order to characterize the stationary points (Section IIIC). The minimum energy paths along the bending angle HXY have been obtained for planar HCNO, HNCO, and HOCN by relaxing the other coordinates (Section III C).

\section{ELECTRONIC STRUCTURE CALCULATIONS}

The $a b$ initio calculations presented below have been carried out by means of the coupled-cluster method, which explicitly includes all single and double excitations, as well as an noniterative perturbative treatment of connected triple substitutions. Dunning's correlation consistent double $(\mathrm{X}=2)$, triple $(\mathrm{X}=3)$, quadruple $(\mathrm{X}=\mathrm{Q})$, quintuple $(X=5)$, and sextuple $(X=6)$ polarized valence basis sets, commonly termed cc-pVXZ, have been used. ${ }^{29}$

Initially only valence electrons were correlated (the frozen-core approximation). Our test calculations for all-electron correlation, however, quickly showed that inclusion of the three $1 s$-like core orbitals located on carbon, nitrogen, and oxygen into the active space has an important influence on the geometrical parameters of HCNO. We have, thus, decided to study in detail also the correlation consistent polarized core-valence basis sets, usually called cc-pCVXZ, employing $\mathrm{X}=2-5$. The cc-pCVXZ basis set family was developed by Woon and Dunning, ${ }^{30}$ by augmenting the original cc-pVXZ sets with supplementary functions especially designed for core-core and core-valence correlations. In the case of cc-pCV5Z, representing the highest quality cc-pCVXZ basis set employed in the current work, the standard ccpV5Z set is extended by adding $(4 s, 4 p, 3 d, 2 f, 1 g)$, leading to $(18 s, 12 p, 7 d, 5 f, 3 g, 1 h) \rightarrow[10 s, 9 p, 7 d, 5 f, 3 g, 1 h]$ for carbon, nitrogen, and oxygen, whereas we have $(8 s, 4 p, 3 d, 2 f, 1 g) \rightarrow[5 s, 4 p, 3 d, 2 f, 1 g]$ for hydrogen. For $[\mathrm{H}, \mathrm{C}, \mathrm{N}, \mathrm{O}]$, the basis sets cc-pV5Z and cc-pCV5Z contain 328 and 490 contracted Gaussian-type orbitals, respectively.

Full geometry optimizations were performed for each of the basis sets employed. To characterize the nature of the stationary points, Hessian matrices were computed and diagonalized. All calculations were performed with the MOLPRO quantum chemistry program package, ${ }^{31}$ with the implementations of the CCSD method due to Hampel et al. ${ }^{32}$ and of the perturbative triple corrections due to Deegan and Knowles ${ }^{33}$. Numerical derivatives were used in the geometry optimization and harmonic vibrational frequency computations, following the procedure of Eckert et al. ${ }^{34}$ and of Rauhut et al., ${ }^{35}$ respectively.

The coordinate space was parametrized in terms of bond-distance-bond-angle coordinates, described by three bond lengths, $r(\mathrm{HX}), r(\mathrm{XY})$, and $r(\mathrm{YZ})$, two inplane bending angles, $\angle(\mathrm{HXY})$ and $\angle(\mathrm{XYZ})$, and one 
dihedral angle for a HXYZ molecule.

\section{RESULTS}

HCNO, HNCO, and HOCN belong to the class of molecules with sixteen valence electrons, which includes e.g. $\mathrm{CO}_{2}$ and $\mathrm{HN}_{3} .{ }^{36}$ Previous studies indicated that the three isomers studied here possess planar equilibrium structures of trans type. ${ }^{13}$ In $C_{s}$ symmetry, the reference (SCF) electronic configuration is given by (same) $\left(1 a^{\prime \prime}\right)^{2}\left(8 a^{\prime}\right)^{2}\left(2 a^{\prime \prime}\right)^{2}\left(9 a^{\prime}\right)^{2}$ for HCNO and by (same) $\left(1 a^{\prime \prime}\right)^{2}\left(8 a^{\prime}\right)^{2}\left(9 a^{\prime}\right)^{2}\left(2 a^{\prime \prime}\right)^{2}$ for HNCO and HOCN, where the common contribution (same) reads $\left(1 a^{\prime}\right)^{2}\left(2 a^{\prime}\right)^{2}\left(3 a^{\prime}\right)^{2}\left(4 a^{\prime}\right)^{2}\left(5 a^{\prime}\right)^{2}\left(6 a^{\prime}\right)^{2}\left(7 a^{\prime}\right)^{2}$. In the $A^{\prime}$ ground electronic state, the highest occupied orbital of $\mathrm{HNCO}$ and $\mathrm{HOCN}$ is thus the nonbonding outof-plane $2 a^{\prime \prime}$ orbital. One may note that the orbitals $\left(8 a^{\prime}, 1 a^{\prime \prime}\right)$ and $\left(9 a^{\prime}, 2 a^{\prime \prime}\right)$ of HCNO at the nonlinear $\operatorname{CCSD}(\mathrm{T})$ equilibrium geometry (see Tab. I) have nearly degenerate RHF/cc-pV5Z energies of respectively $\left(-0.6786 E_{h},-0.6798 E_{h}\right)$ and $\left(-0.4094 E_{h},-0.4096 E_{h}\right)$, resembling a linear molecule situation ( $\pi$ orbitals).

The RHF/cc-pV5Z dipole moment vector for the $\mathrm{CCSD}(\mathrm{T}) / \mathrm{cc}-\mathrm{pV} 5 \mathrm{Z}$ equilibrium structures has magnitudes of $4.225 \mathrm{D}, 2.245 \mathrm{D}$, and $4.053 \mathrm{D}$ for HCNO, HNCO, and HOCN, respectively and magnitudes of 4.290 $\mathrm{D}, 3.260 \mathrm{D}$, and $2.164 \mathrm{D}$ at the lowest energy linear geometries. The components $\left(\left|\mu_{a}\right|,\left|\mu_{b}\right|\right)$ of the dipole moment vector are $(0.234 \mathrm{D}, 4.218 \mathrm{D})$ for HCNO, (1.569 $\mathrm{D}, 1.619 \mathrm{D})$ for $\mathrm{HNCO}$, and $(1.642 \mathrm{D}, 3.715 \mathrm{D})$ for HOCN.

The quality of coupled cluster results with respect to a single reference electron correlation procedure may be assessed by means of the $T_{1}$ diagnostic ${ }^{37}$ which gives the norm of the $t_{1}$ amplitude. It is believed that CCSD may cope with nondynamical correlation up to a $T_{1}$ diagnostic of 0.02 , as recommended in Refs. 37,38. In the case of the CHNO isomers, the highest $T_{1}$ diagnostic value of ca. 0.02 is found for cc-pVXZ with only valence correlation, dropping to ca. 0.018 in the case of all-electron correlation. Beyond the frozen core approximation, we obtained $T_{1}$ of ca. 0.016 and 0.013 for HNCO and HOCN, respectively. Our result for HNCO is compatible with the finding of East et al. ${ }^{18}$ who reported the $T_{1}$ diagnostic for the valence correlation case, and concluded that the multireference character is not very high in HNCO.

In the following text, (all) following a basis set identification indicates that all electrons are included in the correlation treatment.

\section{A. Equilibrium structures}

Tables I, II, and III contain the geometrical parameters for planar and linear conformations of HCNO, HNCO, and HOCN, respectively. The geometries were optimized at the $\operatorname{CCSD}(\mathrm{T})$ level of theory employing two families of basis sets, cc-pVXZ and cc-pCVXZ. Valence and all electron correlations were evaluated. In Tables I, II, and III structural parameters obtained for the basis set of highest quality are highlighted by bold numbers. Equilibrium rotational constants $A_{e}, B_{e}, C_{e}$ were determined and are collected in Table IV for selected basis sets. Table $\mathrm{V}$ provides an overview of the relative energies of the isomers. Our results for cc-pVDZ, cc-pVTZ, and ccpVQZ basis sets displayed in TableI for HCNO agree perfectly with the values previously reported by Koput et al. ${ }^{14}$ The equilibrium $\operatorname{CCSD}(\mathrm{T}) / \mathrm{cc}-\mathrm{pVQZ}$ geometry obtained for HOCN by Schuurman et al. ${ }^{16}$ differs however in $r_{e}(\mathrm{CN})=2.1923 \mathrm{a}_{0}$ by $0.0025 \mathrm{a}_{0}$ from our value $r_{e}(\mathrm{CN})=2.1948 \mathrm{a}_{0}$ reported in Table III. On the other hand, our cc-pVXZ results for $X=2-4$ and all electron correlation show excellent agreement with those obtained by Demaison et al. ${ }^{39}$ for planar HNCO and the optimized geometries at cc-pVTZ level calculated in Refs. 40 and 41.

The results for HCNO constrained to planar geometries with the cc-pVXZ series of basis sets and valence correlation only (upper part of TableI), clearly show convergence to better than $\left[0.0003 \mathrm{a}_{0}, 0.0015 \mathrm{a}_{0}, 0.0003\right.$ $\left.\mathrm{a}_{0}, 2.2^{\circ}, 0.5^{\circ}\right]$ for $\left[r_{e}(H C), r_{e}(C N), r_{e}(N O), \angle(\mathrm{HCN})_{e}\right.$, $\left.\angle(\mathrm{CNO})_{e}\right]$ at the final cc-pV6Z level. For the cc-pVXZ series in the all-electron situation, the convergence of the cc-pV5Z(all) results is better than $\left[0.0027 \mathrm{a}_{0}, 0.0040 \mathrm{a}_{0}\right.$, $\left.0.0011 \mathrm{a}_{0}, 0.8^{\circ}, 0.2^{\circ}\right]$, whereas we have $\left[0.0007 \mathrm{a}_{0}, 0.0036\right.$ $\left.\mathrm{a}_{0}, 0.0013 \mathrm{a}_{0}, 4.4^{\circ}, 0.9^{\circ}\right]$ for the cc-pCV5Z(all) values in the cc-pCVXZ(all) series. For HCNO constrained to linear arrangements (lower part of TableI), all three distances are converged within $0.0005 \mathrm{a}_{0}, 0.0040 \mathrm{a}_{0}$, and $0.0020 \mathrm{a}_{0}$ for cc-pV6Z, cc-pV5Z(all), and cc-pCV5Z(all), respectively.

The data in Table I clearly indicate major difficulties to obtain a well converged minimum energy structure, at least in angular space. The HCN bending angle of planar HCNO shows variations up to $30^{\circ}$ upon basis set improvement with a definite tendency towards linearity. One may also note an abrupt change in both the HCN and CNO angles in Fig. 1 in the cc-pVXZ(all) series. The best equilibrium $\mathrm{HCN}$ bending angles are $170.8^{\circ}, 176.4^{\circ}$, and $173.1^{\circ}$ (scatter of $5.6^{\circ}$ ) with cc-pV6Z, cc-pV5Z(all), and cc-pCV5Z(all) basis sets, and equilibrium CNO angles of $177.9^{\circ}, 179.2^{\circ}$, and $178.4^{\circ}$ (scatter of $1.4^{\circ}$ ), respectively. Inspection of the lower part of Table I with results for linear HCNO reveals that the HCNO molecule is in reality linear at the $\operatorname{CCSD}(\mathrm{T}) / \mathrm{cc}-\mathrm{pV} 6 \mathrm{Z}, \operatorname{CCSD}(\mathrm{T}) / \mathrm{cc}-$ pV5Z(all), and CCSD(T)/cc-pCV5Z(all) levels of theory, the linear form being more stable by a fraction of a $\mathrm{cm}^{-1}$. The failure of the unconstrained optimization to reach this structure indicates a large and exceedingly flat region of the potential energy surface with energy changes near the numerical accuracy limit of standard total energy calculations. One may note that the optimized planar and linear HCNO conformations possess very similar bond lengths. The convergence to the linear arrangement as the electronic minimum is clearly bet- 
TABLE I: Total energies $\mathrm{E}_{\min }$ and $\mathrm{E}_{l i n}$ at optimized planar and linear configurations, bond lengths (in $a_{0}$ ), and bond angles (in degrees) for fulminic acid, HCNO, obtained at the CCSD(T) level of theory for cc-pVXZ (X=2-6) and cc-pCVXZ (X=2-5) basis sets. The height of the barrier to linearity is calculated as $\mathrm{E}_{b a r}=\mathrm{E}_{l i n}-\mathrm{E}_{\min }$. All electron results for the basis sets cc-pVXZ and cc-pCVXZ are denoted by cc-pVXZ(all) and cc-pCVXZ(all), respectively.

\begin{tabular}{|c|c|c|c|c|c|c|}
\hline planar $\mathrm{HCNO}$ & $r_{e}(\mathrm{HC})$ & $r_{e}(\mathrm{CN})$ & $r_{e}(\mathrm{NO})$ & $\angle(\mathrm{HCN})_{e}$ & $\angle(\mathrm{CNO})_{e}$ & $\mathrm{E}_{\min } / E_{h}$ \\
\hline $\begin{array}{l}\text { cc-pVDZ } \\
\text { cc-pVTZ } \\
\text { cc-pVQZ } \\
\text { cc-pV5Z } \\
\text { cc-pV6Z }\end{array}$ & $\begin{array}{r}2.0433 \\
2.0085 \\
2.0059 \\
2.0051 \\
\mathbf{2 . 0 0 4 8}\end{array}$ & $\begin{array}{r}2.2601 \\
2.2152 \\
2.2012 \\
2.1971 \\
\mathbf{2 . 1 9 5 6}\end{array}$ & $\begin{array}{r}2.2750 \\
2.2722 \\
2.2724 \\
2.2742 \\
\mathbf{2 . 2 7 4 5}\end{array}$ & $\begin{array}{r}146.24 \\
157.61 \\
165.14 \\
168.65 \\
\mathbf{1 7 0 . 8 4}\end{array}$ & $\begin{array}{r}171.96 \\
174.83 \\
176.58 \\
177.35 \\
\mathbf{1 7 7 . 8 8}\end{array}$ & $\begin{array}{r}-168.158163 \\
-168.321390 \\
-168.372212 \\
-168.388547 \\
\mathbf{- 1 6 8 . 3 9 4 2 6 3}\end{array}$ \\
\hline $\begin{array}{l}\text { cc-pVDZ(all) } \\
\text { cc-pVTZ(all) } \\
\text { cc-pVQZ(all) } \\
\text { cc-pV5Z(all) }\end{array}$ & $\begin{array}{r}2.0415 \\
1.9981 \\
1.9998 \\
\mathbf{1 . 9 9 7 1}\end{array}$ & $\begin{array}{r}2.2581 \\
2.2074 \\
2.1918 \\
\mathbf{2 . 1 8 7 8}\end{array}$ & $\begin{array}{r}2.2736 \\
2.2636 \\
2.2690 \\
\mathbf{2 . 2 7 0 1}\end{array}$ & $\begin{array}{r}146.71 \\
158.97 \\
175.64 \\
\mathbf{1 7 6 . 4 5}\end{array}$ & $\begin{array}{r}172.11 \\
175.39 \\
179.02 \\
\mathbf{1 7 9 . 2 3}\end{array}$ & $\begin{array}{r}-168.164556 \\
-168.365137 \\
-168.463134 \\
\mathbf{- 1 6 8 . 4 9 8 7 8 6}\end{array}$ \\
\hline $\begin{array}{l}\text { cc-pCVDZ(all) } \\
\text { cc-pCVTZ(all) } \\
\text { cc-pCVQZ(all) } \\
\text { cc-pCV5Z(all) }\end{array}$ & $\begin{array}{r}2.0398 \\
2.0069 \\
2.0030 \\
\mathbf{2 . 0 0 2 3}\end{array}$ & $\begin{array}{r}2.2548 \\
2.2077 \\
2.1945 \\
\mathbf{2 . 1 9 0 9}\end{array}$ & $\begin{array}{r}2.2736 \\
2.2636 \\
2.2693 \\
\mathbf{2 . 2 7 0 6}\end{array}$ & $\begin{array}{r}147.00 \\
159.98 \\
168.76 \\
\mathbf{1 7 3 . 1 3}\end{array}$ & $\begin{array}{r}172.21 \\
175.43 \\
177.44 \\
\mathbf{1 7 8 . 3 6}\end{array}$ & $\begin{array}{r}-168.278027 \\
-168.484504 \\
-168.546525 \\
\mathbf{- 1 6 8 . 5 6 5 7 5 9}\end{array}$ \\
\hline linear $\mathrm{HCNO}$ & $r_{e}(\mathrm{HC})$ & $r_{e}(\mathrm{CN})$ & $r_{e}(\mathrm{NO})$ & $\mathrm{E}_{l i n} / E_{h}$ & $\mathrm{E}_{\text {bar }} / \mathrm{cm}^{-1}$ & \\
\hline $\begin{array}{l}\text { cc-pVDZ } \\
\text { cc-pVTZ } \\
\text { cc-pVQZ } \\
\text { cc-pV5Z } \\
\text { cc-pV6Z }\end{array}$ & $\begin{array}{r}2.0318 \\
2.0042 \\
2.0041 \\
2.0041 \\
\mathbf{2 . 0 0 4 2}\end{array}$ & $\begin{array}{r}2.2326 \\
2.2034 \\
2.1959 \\
2.1940 \\
\mathbf{2 . 1 9 3 5}\end{array}$ & $\begin{array}{r}2.2855 \\
2.2777 \\
2.2750 \\
2.2757 \\
\mathbf{2 . 2 7 5 7}\end{array}$ & $\begin{array}{r}-168.156973 \\
-168.321197 \\
-168.372179 \\
-168.388542 \\
\mathbf{- 1 6 8 . 3 9 4 2 6 4}\end{array}$ & $\begin{array}{r}261.34 \\
42.38 \\
7.44 \\
0.81 \\
\mathbf{- 0 . 3 3}\end{array}$ & \\
\hline $\begin{array}{l}\text { cc-pVDZ(all) } \\
\text { cc-pVTZ(all) } \\
\text { cc-pVQZ(all) } \\
\text { cc-pV5Z(all) }\end{array}$ & $\begin{array}{r}2.0304 \\
1.9950 \\
1.9997 \\
\mathbf{1 . 9 9 6 9}\end{array}$ & $\begin{array}{r}2.2315 \\
2.1976 \\
2.1914 \\
\mathbf{2 . 1 8 7 5}\end{array}$ & $\begin{array}{r}2.2839 \\
2.2684 \\
2.2692 \\
\mathbf{2 . 2 7 0 2}\end{array}$ & $\begin{array}{r}-168.163439 \\
-168.364961 \\
-168.463134 \\
\mathbf{- 1 6 8 . 4 9 8 7 8 8}\end{array}$ & $\begin{array}{r}245.13 \\
38.68 \\
-0.03 \\
\mathbf{- 0 . 4 4}\end{array}$ & \\
\hline $\begin{array}{l}\text { cc-pCVDZ(all) } \\
\text { cc-pCVTZ (all) } \\
\text { cc-pCVQZ (all) } \\
\text { cc-pCV5Z (all) }\end{array}$ & $\begin{array}{r}2.0287 \\
2.0036 \\
2.0019 \\
\mathbf{2 . 0 0 1 7}\end{array}$ & $\begin{array}{r}2.2286 \\
2.1983 \\
2.1916 \\
\mathbf{2 . 1 8 9 6}\end{array}$ & $\begin{array}{r}2.2832 \\
2.2727 \\
2.2708 \\
\mathbf{2 . 2 7 1 3}\end{array}$ & $\begin{array}{r}-168.276957 \\
-168.484389 \\
-168.546515 \\
\mathbf{- 1 6 8 . 5 6 5 7 6 3}\end{array}$ & $\begin{array}{r}234.42 \\
23.44 \\
2.19 \\
\mathbf{- 0 . 8 7}\end{array}$ & \\
\hline
\end{tabular}
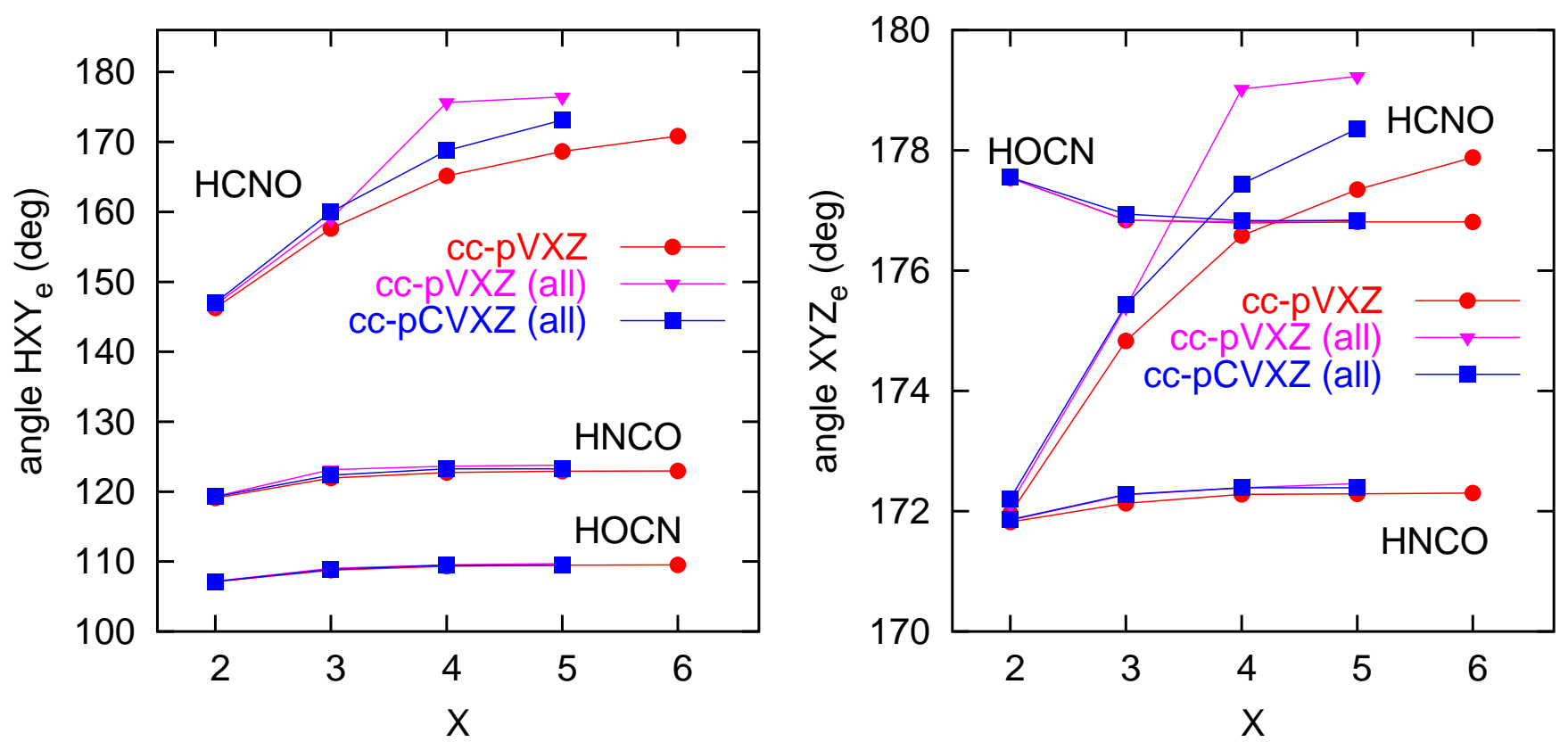

FIG. 1: Variation of the equilibrium HXY and XYZ angles with the cardinal number $X$ of the cc-pVXZ, cc-pVXZ(all), and cc-pCVXZ(all) basis sets for planar HCNO, HNCO, and HOCN. 
TABLE II: Optimized structural parameters of isocyanic acid, HNCO. For more details, see Table I.

\begin{tabular}{|c|c|c|c|c|c|c|}
\hline planar HNCO & $r_{e}(\mathrm{HN})$ & $r_{e}(\mathrm{NC})$ & $r_{e}(\mathrm{CO})$ & $\angle(\mathrm{HNC})_{e}$ & $\angle(\mathrm{NCO})_{e}$ & $\mathrm{E}_{\min } / E_{h}$ \\
\hline cc-pVDZ & 1.9240 & 2.3376 & 2.2266 & 119.10 & 171.82 & -168.268465 \\
\hline cc-pVTZ & 1.9004 & 2.3083 & 2.2106 & 121.95 & 172.13 & -168.432782 \\
\hline cc-pVQZ & 1.8982 & 2.3015 & 2.2040 & 122.72 & 172.28 & -168.484107 \\
\hline cc-pV5Z & 1.8983 & 2.3004 & 2.2029 & 122.91 & 172.29 & -168.500436 \\
\hline cc-pV6Z & 1.8984 & 2.2999 & 2.2025 & 122.96 & 172.30 & -168.506138 \\
\hline cc-pVDZ(all) & 1.9224 & 2.3357 & 2.2257 & 119.29 & 171.85 & -168.274865 \\
\hline cc-pVTZ(all) & 1.8948 & 2.2987 & 2.2051 & 123.14 & 172.27 & -168.475476 \\
\hline cc-pVQZ(all) & 1.8932 & 2.2942 & 2.1997 & 123.62 & 172.39 & -168.574631 \\
\hline cc-pV5Z(all) & 1.8934 & 2.2914 & 2.1969 & 123.78 & 172.46 & -168.610519 \\
\hline cc-pCVDZ(all) & 1.9218 & 2.3336 & 2.2238 & 119.27 & 171.86 & -168.388591 \\
\hline cc-pCVTZ(all) & 1.8978 & 2.3023 & 2.2059 & 122.37 & 172.28 & -168.595999 \\
\hline cc-pCVQZ(all) & 1.8958 & 2.2955 & 2.2000 & 123.27 & 172.39 & -168.658308 \\
\hline cc-pCV5Z(all) & 1.8956 & 2.2943 & 2.1988 & 123.50 & 172.40 & -168.677463 \\
\hline linear $\mathrm{HNCO}$ & $r_{e}(\mathrm{HN})$ & $r_{e}(\mathrm{NC})$ & $r_{e}(\mathrm{CO})$ & $\mathrm{E}_{\text {lin }} / E_{h}$ & $\mathrm{E}_{\text {bar }} / \mathrm{cm}^{-1}$ & \\
\hline cc-pVDZ & 1.8836 & 2.2587 & 2.2471 & -168.257037 & 2508 & \\
\hline cc-pVTZ & 1.8655 & 2.2347 & 2.2298 & -168.423660 & 2002 & \\
\hline cc-pVQZ & 1.8654 & 2.2302 & 2.2231 & -168.475344 & 1923 & \\
\hline cc-pV5Z & 1.8658 & 2.2295 & 2.2220 & -168.491746 & 1907 & \\
\hline cc-pV6Z & 1.8659 & 2.2292 & 2.2216 & -168.497487 & 1899 & \\
\hline cc-pVDZ(all) & 1.8824 & 2.2576 & 2.2460 & -168.263635 & 2465 & \\
\hline cc-pVTZ(all) & 1.8609 & 2.2287 & 2.2239 & -168.467642 & 1721 & \\
\hline cc-pVQZ(all) & 1.8617 & 2.2258 & 2.2181 & -168.566668 & 1748 & \\
\hline cc-pV5Z(all) & 1.8622 & 2.2230 & 2.2155 & -168.602508 & 1758 & \\
\hline cc-pCVDZ(all) & 1.8812 & 2.2549 & 2.2442 & -168.377392 & 2458 & \\
\hline cc-pCVTZ(all) & 1.8643 & 2.2302 & 2.2251 & -168.587091 & 1952 & \\
\hline cc-pCVQZ(all) & 1.8639 & 2.2262 & 2.2188 & -168.649892 & 1847 & \\
\hline cc-pCV5Z(all) & 1.8641 & 2.2254 & 2.2176 & -168.669183 & 1817 & \\
\hline
\end{tabular}

ter in the all electron calculations. A linear equilibrium structure is compatible with the results of Bunker et al. ${ }^{10}$ who used the semirigid bender model to study the rovibrational spectra of $\mathrm{HCNO}$ and concluded that $\mathrm{HCNO}$ is likely linear with an equilibrium geometry of $\left[\mathrm{r}_{e}(\mathrm{HN})\right.$, $\left.\mathrm{r}_{e}(\mathrm{NC}), \mathrm{r}_{e}(\mathrm{CO})\right]$ equal to $\left[2.0031 \mathrm{a}_{0}, 2.2091 \mathrm{a}_{0}, 2.2658\right.$ $\left.a_{0}\right]$. These values exhibit, however, noticeable deviations (up to $0.02 \mathrm{a}_{0}$ ) from our results (Table I) for both linear and planar conformations.

The equilibrium heavy atom XYZ bending angle found in planar arrangement optimizations is larger than $170^{\circ}$ for all three isomers, i.e. ca. $178^{\circ}$ for $\mathrm{HCNO}, 177^{\circ}$ for HOCN, and $172^{\circ}$ for HNCO. A quick glance at Tables II and III reveals that the equilibrium bending angles of HNCO and HOCN are, unlike HCNO, very stable during the geometry optimization within each series of basis sets, showing only minor and monotonic changes. Going from triple to quintuple $\zeta$ basis set quality, the HXY and XYZ angles vary by at most $1^{\circ}$ and $0.2^{\circ}$, respectively, and converge to very similar values (bold numbers). This is also evident from Fig. 1, which shows the equilibrium HXY and XYZ angles as functions of the basis set cardinal number $X$. Excellent and almost universally monotonic convergence within each series is observed for interatomic distances with, however, somewhat different final values.

Experimental determinations of the equilibrium structure of HOCN are not available due to the absence of gas phase observations. For HNCO East et al. derived ${ }^{18}$ an empirical equilibrium structure of $\left[\mathrm{r}_{e}(\mathrm{HN}), \mathrm{r}_{e}(\mathrm{NC})\right.$, $\left.\mathrm{r}_{e}(\mathrm{CO}), \angle(\mathrm{HNC})_{e}, \angle(\mathrm{NCO})_{e}\right]$ equal to $\left[1.8954 \mathrm{a}_{0}, 2.2953\right.$ $\left.\mathrm{a}_{0}, 2.1985 \mathrm{a}_{0}, 123.34^{\circ}, 172.22^{\circ}\right]$ from the known experimental rotational constants $A_{0}, B_{0}, C_{0}$ and theoretical rotation-vibration coupling constants $\left(\alpha_{e}\right)$. Among our HNCO results of Table II, the CCSD $(\mathrm{T}) / \mathrm{cc}-\mathrm{pCV} 5 \mathrm{Z}$ (all) values show the best agreement within $\left[0.0002 \mathrm{a}_{0},-0.0010\right.$ $\left.\mathrm{a}_{0}, 0.0003 \mathrm{a}_{0}, 0.16^{\circ}, 0.18^{\circ}\right]$ with the finding from Ref. 18 . This is a very encouraging result because this should be the most consistent combination of basis set and correlation approach. The importance of the core correlation effect for the prediction of the HNCO angles was previously pointed out by Demaison et al. ${ }^{39}$

The variation of the absolute equilibrium energy of HCNO (Table I) with the basis set cardinal number $X$ is graphically presented in Fig. 2. Only the planar case is shown, since energies of planar and linear HCNO appear identical on the scale of the figure. The absolute difference between the $X=4$ and $X=5$ results in Fig. 2 is ca. $0.016,0.036$, and $0.019 E_{h}$ for cc-pVXZ, cc-pVXZ(all), and cc-pCVXZ(all), respectively.

The equilibrium rotational constants calculated from the structural parameters of Tables I, II, and III are summarized in Table IV. For these evaluations, the atomic masses for ${ }^{1} \mathrm{H},{ }^{12} \mathrm{C},{ }^{14} \mathrm{~N}$, and ${ }^{16} \mathrm{O}$ are taken from Ref. 42 . For each of the three CHNO isomers, the constants $\mathrm{B}_{e}$, 
TABLE III: Optimized structural parameters of cyanic acid, HOCN. For more details, see Table I.

\begin{tabular}{|c|c|c|c|c|c|c|}
\hline planar $\mathrm{HOCN}$ & $r_{e}(\mathrm{HO})$ & $r_{e}(\mathrm{OC})$ & $r_{e}(\mathrm{CN})$ & $\angle(\mathrm{HOC})_{e}$ & $\angle(\mathrm{OCN})_{e}$ & $\mathrm{E}_{\min } / E_{h}$ \\
\hline cc-pVDZ & 1.8371 & 2.4907 & 2.2294 & 107.12 & 177.54 & -168.231416 \\
\hline cc-pVTZ & 1.8247 & 2.4713 & 2.2016 & 108.76 & 176.84 & -168.394918 \\
\hline cc-pVQZ & 1.8213 & 2.4632 & 2.1948 & 109.34 & 176.79 & -168.445427 \\
\hline cc-pV5Z & 1.8213 & 2.4614 & 2.1935 & 109.49 & 176.81 & -168.461521 \\
\hline cc-pV6Z & 1.8214 & 2.4607 & 2.1931 & 109.54 & 176.81 & -168.467105 \\
\hline cc-pVDZ(all) & 1.8361 & 2.4887 & 2.2283 & 107.18 & 177.54 & -168.237624 \\
\hline cc-pVTZ(all) & 1.8217 & 2.4625 & 2.1947 & 109.02 & 176.84 & -168.436786 \\
\hline cc-pVQZ(all) & 1.8181 & 2.4563 & 2.1896 & 109.53 & 176.81 & -168.535393 \\
\hline cc-pV5Z(all) & 1.8180 & 2.4542 & 2.1865 & 109.71 & 176.84 & -168.571113 \\
\hline cc-pCVDZ(all) & 1.8358 & 2.4879 & 2.2255 & 107.16 & 177.55 & -168.351416 \\
\hline cc-pCVTZ(all) & 1.8226 & 2.4665 & 2.1954 & 108.88 & 176.94 & -168.558021 \\
\hline cc-pCVQZ (all) & 1.8199 & 2.4581 & 2.1898 & 109.49 & 176.83 & -168.619465 \\
\hline cc-pCV5Z(all) & 1.8195 & 2.4561 & 2.1884 & 109.66 & 176.83 & -168.638383 \\
\hline linear HOCN & $r_{e}(\mathrm{HO})$ & $r_{e}(\mathrm{OC})$ & $r_{e}(\mathrm{CN})$ & $\mathrm{E}_{l i n} / E_{h}$ & $\mathrm{E}_{b a r} / \mathrm{cm}^{-1}$ & \\
\hline cc-pVDZ & 1.7910 & 2.3897 & 2.2366 & -168.181592 & 10935 & \\
\hline cc-pVTZ & 1.7821 & 2.3699 & 2.2081 & -168.349713 & 9921 & \\
\hline cc-pVQZ & 1.7807 & 2.3641 & 2.2016 & -168.401664 & 9605 & \\
\hline cc-pV5Z & 1.7814 & 2.3631 & 2.2003 & -168.418284 & 9489 & \\
\hline cc-pV6Z & 1.7817 & 2.3627 & 2.1999 & -168.424029 & 9453 & \\
\hline cc-pVDZ(all) & 1.7902 & 2.3883 & 2.2353 & -168.187964 & 10901 & \\
\hline cc-pVTZ(all) & 1.7784 & 2.3616 & 2.2008 & -168.393175 & 9571 & \\
\hline cc-pVQZ(all) & 1.7779 & 2.3583 & 2.1961 & -168.492441 & 9427 & \\
\hline cc-pV5Z(all) & 1.7785 & 2.3567 & 2.1930 & -168.528489 & 9355 & \\
\hline cc-pCVDZ(all) & 1.7896 & 2.3870 & 2.2327 & -168.301688 & 10914 & \\
\hline cc-pCVTZ(all) & 1.7803 & 2.3662 & 2.2021 & -168.513099 & 9859 & \\
\hline cc-pCVQZ(all) & 1.7795 & 2.3601 & 2.1965 & -168.576113 & 9515 & \\
\hline cc-pCV5Z(all) & 1.7799 & 2.3590 & 2.1951 & -168.595591 & 9392 & \\
\hline
\end{tabular}

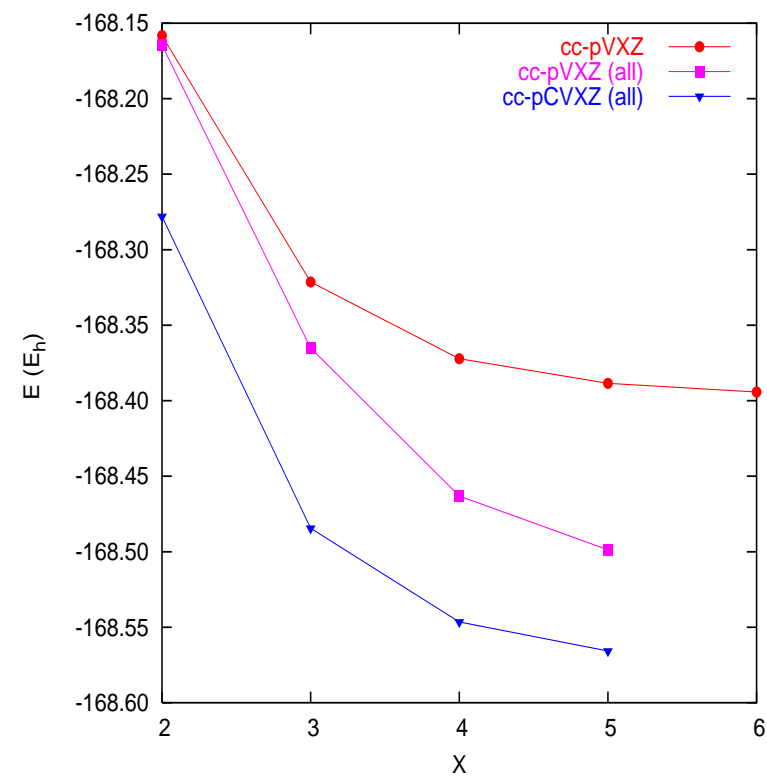

FIG. 2: Absolute CCSD(T) energy of optimized planar $\mathrm{HCNO}$ as a function of the cardinal number $X$ of the ccpVXZ, cc-pVXZ(all), and cc-pCVXZ(all) basis set families.
TABLE IV: Rotational constants (in $\mathrm{cm}^{-1}$ ) of HCNO, HNCO, and HOCN, calculated using the structural parameters reported in Tables I, II, and III. Here, $\mathrm{B}_{\text {lin }}$ stands for the rotational constant at the optimum linear arrangement.

\begin{tabular}{l|cccc}
\hline \hline HCNO & $\mathrm{A}_{e}$ & $\mathrm{~B}_{e}$ & $\mathrm{C}_{e}$ & $\mathrm{~B}_{\text {lin }}$ \\
\hline cc-pV6Z & 793 & 0.38250 & 0.38232 & 0.38214 \\
cc-pCV5Z(all) & 1410 & 0.38374 & 0.38364 & 0.38352 \\
cc-pV5Z(all) & 5315 & 0.38419 & 0.38417 & 0.38416 \\
\hline HNCO & $\mathrm{A}_{e}$ & $\mathrm{~B}_{e}$ & $\mathrm{C}_{e}$ & $\mathrm{~B}_{\text {lin }}$ \\
\hline cc-pV6Z & 27.659 & 0.36932 & 0.36445 & 0.36390 \\
cc-pCV5Z(all) & 28.138 & 0.37060 & 0.36578 & 0.36515 \\
cc-pV5Z(all) & 28.415 & 0.37128 & 0.36649 & 0.36588 \\
\hline HOCN & $\mathrm{A}_{e}$ & $\mathrm{~B}_{e}$ & $\mathrm{C}_{e}$ & $\mathrm{~B}_{l i n}$ \\
\hline cc-pV6Z & 22.382 & 0.35256 & 0.34709 & 0.35108 \\
cc-pCV5Z (all) & 22.467 & 0.35393 & 0.34844 & 0.35235 \\
cc-pV5Z(all) & 22.520 & 0.35448 & 0.34899 & 0.35303 \\
\hline \hline
\end{tabular}

$\mathrm{C}_{e}$, and $\mathrm{B}_{l i n}$ in Table IV agree within ca. $0.002 \mathrm{~cm}^{-1}(0.5$ $\%)$. The scatter of rotational $\mathrm{A}_{e}$ constants is $0.8 \mathrm{~cm}^{-1}$ $(2.7 \%)$ and $0.1 \mathrm{~cm}^{-1}(0.6 \%)$ for HNCO and HOCN, respectively. One may note that the two $\mathrm{A}_{e}$ values obtained by correlating all electrons agree within $1 \%$ for $\mathrm{HNCO}$ 
TABLE V: Energies (in $\mathrm{cm}^{-1}$ ) of optimized planar and linear HCNO and HOCN measured relative to the energy of the respective equilibrium $\mathrm{HNCO}$ configuration.

\begin{tabular}{|c|c|c|c|c|}
\hline & planar HOCN & linear $\mathrm{HOCN}$ & planar $\mathrm{HCNO}$ & linear $\mathrm{HCNO}$ \\
\hline cc-pVDZ & 8131 & 19066 & 24208 & 24470 \\
\hline cc-pVTZ & 8310 & 18231 & 24448 & 24490 \\
\hline cc-pVQZ & 8489 & 18094 & 24558 & 24565 \\
\hline cc-pV5Z & 8541 & 18030 & 24557 & 24558 \\
\hline cc-pV6Z & 8567 & 18020 & 24554 & 24554 \\
\hline cc-pVDZ(all) & 8173 & 19073 & 24210 & 24455 \\
\hline cc-pVTZ(all) & 8491 & 18063 & 24217 & 24255 \\
\hline cc-pVQZ(all) & 8612 & 18039 & 24471 & 24471 \\
\hline cc-pV5Z(all) & 8647 & 18004 & 24523 & 24522 \\
\hline cc-pCVDZ(all) & 8159 & 19073 & 24266 & 24500 \\
\hline cc-pCVTZ(all) & 8335 & 18194 & 24471 & 24496 \\
\hline cc-pCVQZ(all) & 8525 & 18040 & 24534 & 24536 \\
\hline cc-pCV5Z(all) & 8577 & 17969 & 24516 & 24515 \\
\hline
\end{tabular}

and $0.2 \%$ for HOCN. Since optimized HCNO possesses two very nearly linear bond angles, the calculated $\mathrm{A}_{e}$ constant is rather large.

\section{B. Relative energies}

The barriers to linearity, $\mathrm{E}_{b a r}$, for HCNO, HNCO, and HOCN are given in the lower parts of Tables I, II, and III, respectively. For all three isomers, $\mathrm{E}_{b a r}$ decreases as $X$ increases, due to a somewhat faster lowering of the total energy at the linear arrangements upon increasing $X$. Planar HNCO and planar HOCN are 1907 and $9489 \mathrm{~cm}^{-1}$ more stable than their linear forms in the $\operatorname{CCSD}(\mathrm{T}) / \mathrm{cc}-$ pV5Z calculation. The inclusion of core correlation lowers the barrier to linearity by $149 \mathrm{~cm}^{-1}$ (ca. 8\%) to 1758 $\mathrm{cm}^{-1}$ and by $134 \mathrm{~cm}^{-1}$ (ca. $1.4 \%$ ) to $9355 \mathrm{~cm}^{-1}$, respectively. The cc-pV5Z(all) and cc-pCV5Z(all) results agree within $3 \%$ for $\mathrm{E}_{b a r}(\mathrm{HNCO})$ and $0.4 \%$ for $\mathrm{E}_{b a r}(\mathrm{HNCO})$, Table II. This sensitivity of the barrier height to the level of correlation treatment is somewhat surprising if one considers the excellent consistency of equilibrium structures. A focal-point analysis by Császár at al. ${ }^{40}$ carried out at the optimized $\operatorname{CCSD}(\mathrm{T}) / \mathrm{cc}-\mathrm{pVTZ}$ (all) geometry of HNCO gave a barrier to linearity of 1864 $\mathrm{cm}^{-1}$. The optimized $\operatorname{CCSD}(\mathrm{T}) / \mathrm{cc}-\mathrm{pVTZ}$ (all) geometry $\left[\mathrm{r}_{e}(\mathrm{HN}), \mathrm{r}_{e}(\mathrm{NC}), \mathrm{r}_{e}(\mathrm{CO}), \angle(\mathrm{HNC})_{e}, \angle(\mathrm{NCO})_{e}\right]$ for planar HNCO deviates, however, by $\left[0.0014 \mathrm{a}_{0}, 0.0073 \mathrm{a}_{0}, 0.0082\right.$ $\left.\mathrm{a}_{0},-0.64^{\circ},-0.19^{\circ}\right]$ from the corresponding $\operatorname{CCSD}(\mathrm{T}) / \mathrm{cc}-$ pV5Z(all) value, as seen in Table II. Niedenhoff at al. ${ }^{24}$ derived a semirigid bender result of $\mathrm{E}_{b a r}(\mathrm{HNCO})=1899$ $\mathrm{cm}^{-1}$. This result probably includes some effects due to vibrational averaging. Beyond the present treatment other effects on the HNCO barrier to linearity were found in the systematic study of relativistic corrections ${ }^{41}$.

The relative energies of the CHNO isomers are summarized in Table $\mathrm{V}$. Two of the entries in Table $\mathrm{V}$ can be compared with values obtained in a frozen-core focalpoint study by Schuurman et al. ${ }^{16}$, in which the empirical geometry of East et al. ${ }^{18}$ was used for HNCO, the linear geometry of Koput et al. ${ }^{14}$ for $\mathrm{HCNO}$, and a CCSD(T)/cc-pVQZ optimized geometry for HOCN. Isomerization energies of $8621 \mathrm{~cm}^{-1}$ and $24717 \mathrm{~cm}^{-1}$ were reported for $\mathrm{HOCN} \rightarrow \mathrm{HNCO}$ and $\mathrm{HCNO} \rightarrow \mathrm{HNCO}$, respectively, in the complete basis set (CBS) limit. ${ }^{16}$ These results are 54 and $163 \mathrm{~cm}^{-1}$ larger than our values of 8567 $\mathrm{cm}^{-1}$ and $24554 \mathrm{~cm}^{-1}$, listed for cc-pV6Z in Table V. This discrepancy is solely due to contributions of explicit triple substitutions, which amounts to $56 \mathrm{~cm}^{-1}$ and 130 $\mathrm{cm}^{-1}$ for CCSDT [see Table V of Ref.16]. The influence of core correlation on the two isomerization energies can be estimated from our Table $\mathrm{V}$, which provides a value of 106 and $36 \mathrm{~cm}^{-1}$, respectively, from the cc-pV5Z and cc-pV5Z(all) data.

\section{Vibrational structures}

The variation of the electronic (potential) energy along the minimum energy path (MEP) for the HCN bending angle of HCNO is displayed in Fig. 3. For the basis sets cc-pVXZ, cc-pVXZ(all), and cc-CVXZ(all) with $\mathrm{X}=2-4$, the MEPs were calculated by relaxing the four coordinates $\mathrm{r}(\mathrm{HC}), \mathrm{r}(\mathrm{CN}), \mathrm{r}(\mathrm{NO})$, and $\angle(\mathrm{CNO})$ for preselected values of $\angle(\mathrm{HCN})$ in planar HCNO. In Fig. 3, one may note that the ordering of the MEPs for a given cardinal number $X$ changes in going from $X=2$ to $X=4$. Whereas the CCSD(T)/cc-pVDZ(all) values lie between the other two sets of results for $X=2$, the cc-pCVQZ(all) curve falls between cc-VQZ and cc-VQZ(all) for $X=4$. The cc-pVQZ(all) values display the highest curvature in Fig. 3. The inclusion of core correlation effects leads to a visible stiffening of the bending profiles.

Figure 4 shows the CCSD(T)/cc-pVQZ(all) minimum 


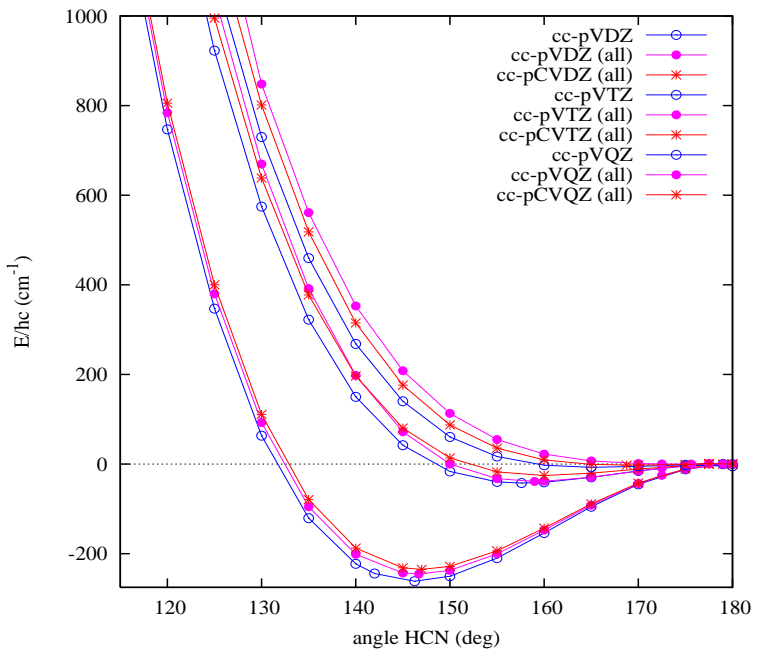

FIG. 3: Minimum energy path along the HCN angle of HCNO, calculated at the $\operatorname{CCSD}(\mathrm{T})$ level of theory for the cc-pVXZ and cc-pCVXZ basis sets using $\mathrm{X}=2-4$. Both valence electron correlation and all electron correlation results are shown. For easier comparison, all profiles are drawn to a common scale.

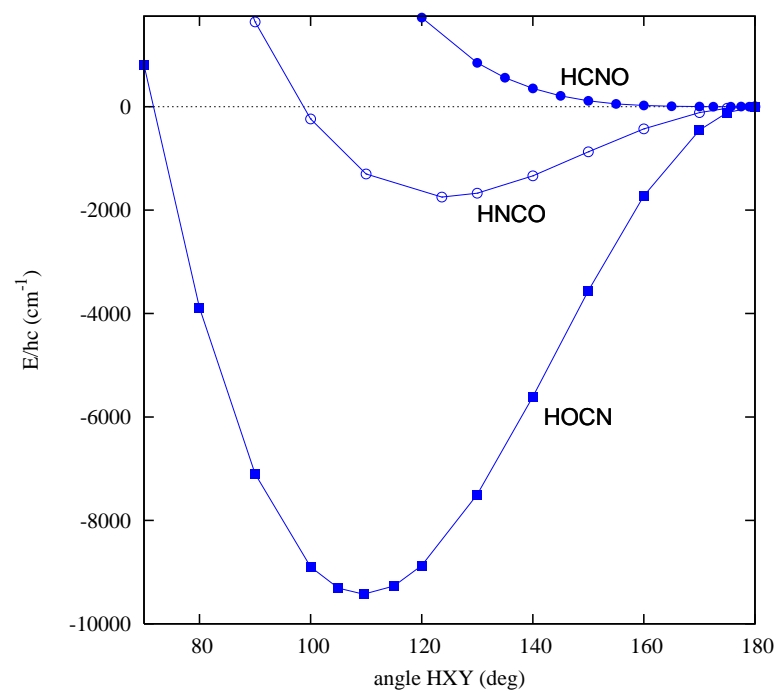

FIG. 4: Minimum energy paths of $\mathrm{HCNO}, \mathrm{HNCO}$, and HOCN from $\operatorname{CCSD}(\mathrm{T})$ calculations with the cc-pVQZ basis set and all electron correlation. Each of the curves shown is measured relative to the energy of the respective optimum linear configuration.

energy paths for planar HCNO, HNCO, and HOCN. Their common feature is a pronounced deviation from harmonic behaviour and a significant angular width. The variation of the optimum bond lengths $\mathrm{r}_{\text {opt }}(\mathrm{HX})$, $\mathrm{r}_{\text {opt }}(\mathrm{XY})$, and $\mathrm{r}_{\text {opt }}(\mathrm{YZ})$ along the MEPs of Fig. 4 is graphically presented in Fig. 5. For the MEP in the direction of the $\mathrm{HCN}$ bending angle of $\mathrm{HCNO}$, the optimum triplet $\left[\mathrm{r}_{\text {opt }}(\mathrm{HC}), \mathrm{r}_{\text {opt }}(\mathrm{CN}), \mathrm{r}_{\text {opt }}(\mathrm{NO})\right]$ assumes the value of $\left[2.032 \mathrm{a}_{0}, 2.262 \mathrm{a}_{0}, 2.243 \mathrm{a}_{0}\right]$ for $\angle(\mathrm{HCN})=120^{\circ}$ and $\left[2.000 \mathrm{a}_{0}, 2.191 \mathrm{a}_{0}, 2.269 \mathrm{a}_{0}\right]$ for $\angle(\mathrm{HCN})=180^{\circ}$, exhibiting changes of $-0.032,-0.071$, and $+0.026 a_{0}$, respectively. The decrease in $\mathrm{r}_{\text {opt }}(\mathrm{HX})$ and $\mathrm{r}_{\text {opt }}(\mathrm{XY})$, accompanied by an increase of $\mathrm{r}_{\text {opt }}(\mathrm{YZ})$, is also observed for HNCO and HOCN upon straightening of the HXY bending angle. These important changes of radial coordinates upon bending have strong effects on the bending dynamics through the reduced mass and typically lead to pronounced coupling between angular and radial vibrational modes in spite of widely differing frequency scales ${ }^{43,44}$. The variation of the CN bond length of HOCN is, however, rather weak, exhibiting changes of only $0.006 \mathrm{a}_{0}$ over the angular range explored in Fig. 5.

In Fig. 6, we compare the $\operatorname{CCSD}(\mathrm{T}) / \mathrm{cc}-\mathrm{pVQZ}$ (all) MEP of HCNO with the MEPs of HCCH and HCCN. In addition to the MEP for the HCN angle, the MEP along the CNO angle is also displayed for HCNO. The potential energy surface of Strey and Mills ${ }^{45}$ is used for $\mathrm{HCCH}$ only for the purpose of illustration. A MR-ACPF PES ${ }^{27}$ is employed for HCCN. The small-amplitude CNO bending vibration in $\mathrm{HCNO}$ clearly resembles the stiff $\mathrm{HCC}$ bending mode of acetylene, a textbook example for linear molecules. The HCN bending mode, on the other side, is similar to the quasi-linear large amplitude HCC mode of HCCN, with the important difference that HCNO exhibits no barrier to linearity.

Coplanar atom arrangements of tetratomic molecules may have either trans or cis form. All the geometry optimizations starting at cis conformations of the CHNO isomers led to "hockey-stick" structures, arrangements with a strictly linear heavy-atom skeleton (we adopt here the terminology of East et al. ${ }^{18}$ ). There appear to be no local minima for cis arrangements. For HCNO, HNCO, and HOCN, the "hockey-stick" structures optimized at the cc-pVQZ(all) level are listed in Table VI. As seen there, the geometry optimization carried out by freezing the CNO subunit of HCNO to be linear led to the linear minimum of Table I. The optimum "hockey-stick" structures of HNCO and HOCN lie 339 and $31 \mathrm{~cm}^{-1}$ above their respective global minima, respectively. In the previous study on $\mathrm{HCCN},{ }^{27}$ this structure was found $84 \mathrm{~cm}^{-1}$ above the minimum. It may be noted that the "hockey-stick" structures are relevant for the description of the torsional (out-of-plane bending) motion in tetratomic molecules.

Harmonic vibrational frequencies are collected in Table VII. The frequencies were evaluated numerically at the geometries optimized for the cc-pVXZ and cc-pVXZ(all) series with $X=2-4$. For HCNO, which has a barrier to linearity of 7.44 and $-0.03 \mathrm{~cm}^{-1}$ for the cc-pVQZ and cc-pVQZ(all) treatments, respectively, the force field analysis was carried out for both the planar and linear configurations of Table I. Two degenerate imaginary frequencies were found for linear HCNO and ccpVQZ. For the two geometrically distinct, but energetically extremely close, $\mathrm{HCNO}$ configurations identified at the cc-pVQZ(all) level, harmonic vibrational frequencies 

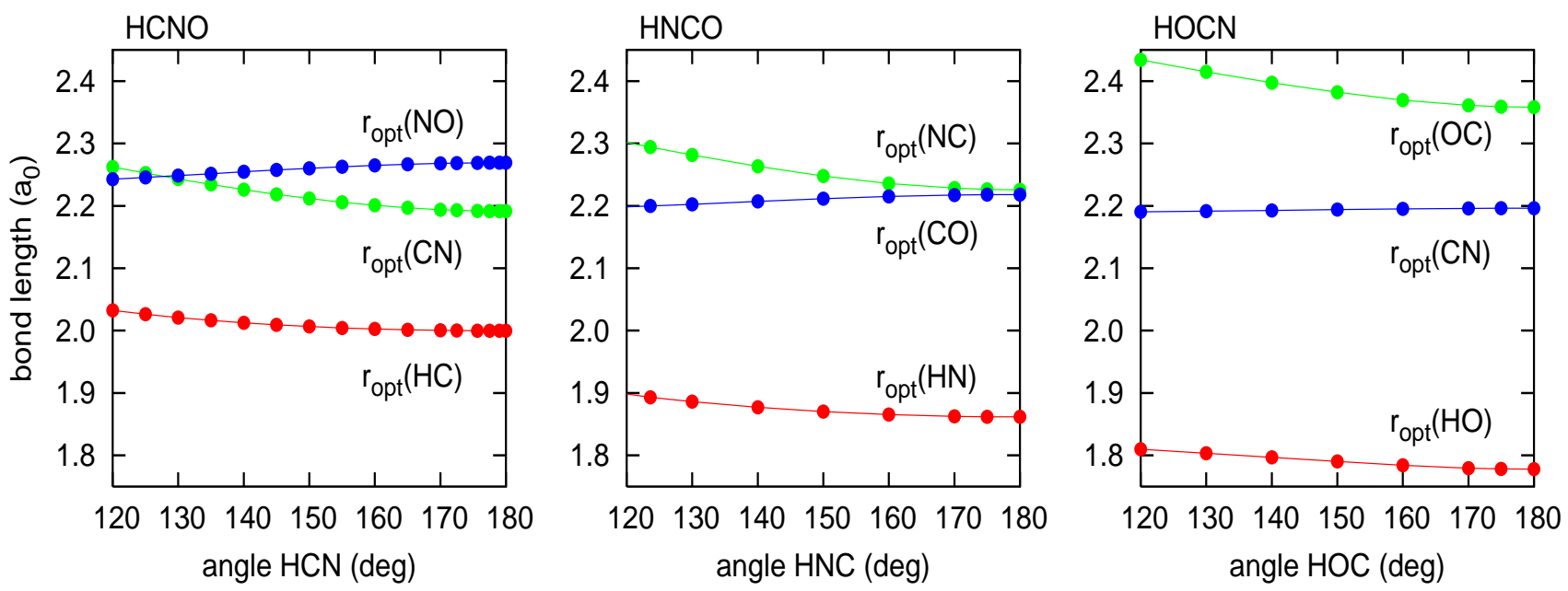

FIG. 5: Variation of the optimum bond lengths $r_{\text {opt }}(\mathrm{HX}), r_{\text {opt }}(\mathrm{XY})$, and $r_{\text {opt }}(\mathrm{YZ})$ of HXYZ along the minimum energy path in the direction of the HXY angle from CCSD(T)/cc-pVQZ(all) calculations. The results are shown for HCNO (left), HNCO (center), and HOCN (right).

TABLE VI: Geometrical parameters for the "hockey-stick" structure of HCNO, HNCO, and HOCN at the CCSD(T)/ccpVQZ(all) level. Bond lengths are given in $a_{0}$ and angles in degrees.

\begin{tabular}{|c|c|c|c|c|c|}
\hline & HCNO & & HNCO & & $\mathrm{HOCN}$ \\
\hline $\begin{array}{l}\mathrm{r}(\mathrm{HC})_{e} \\
\mathrm{r}(\mathrm{CN})_{e} \\
\mathrm{r}(\mathrm{NO})_{e} \\
\angle(\mathrm{HCN})_{e} \\
\angle(\mathrm{CNO})_{e} \\
\mathrm{E} / E_{h}\end{array}$ & $\begin{array}{l}1.9997 \\
2.1914 \\
2.2692 \\
180.0 \\
180.0 \\
-168.463134\end{array}$ & $\begin{array}{l}\mathrm{r}(\mathrm{HN})_{e} \\
\mathrm{r}(\mathrm{NC})_{e} \\
\mathrm{r}(\mathrm{CO})_{e} \\
\angle(\mathrm{HNC})_{e} \\
\angle(\mathrm{NCO})_{e} \\
\mathrm{E} / E_{h}\end{array}$ & $\begin{array}{l}1.8923 \\
2.2895 \\
2.2004 \\
123.34 \\
180.0 \\
-168.573087\end{array}$ & $\begin{array}{l}\mathrm{r}(\mathrm{HO})_{e} \\
\mathrm{r}(\mathrm{OC})_{e} \\
\mathrm{r}(\mathrm{CN})_{e} \\
\angle(\mathrm{HOC})_{e} \\
\angle(\mathrm{OCN})_{e} \\
\mathrm{E} / E_{h}\end{array}$ & $\begin{array}{l}1.8181 \\
2.4566 \\
2.1896 \\
109.26 \\
180.0 \\
-168.535252\end{array}$ \\
\hline
\end{tabular}

are identical, with the exception of the quasi-linear $\mathrm{HCN}$ mode. A clear correlation can be seen between the $\omega_{4}\left(\mathrm{a}^{\prime}\right)$ and $\omega_{6}(\mathrm{a} ")$ modes for planar HCNO on one side and the doubly degenerate CNO mode of linear $\mathrm{HCNO}$ on the other side. These harmonic estimates only give a first overview and will be replaced by a fully coupled anharmonic vibration-rotation treatment.

\section{Computational perspectives}

Since our main interest lies in the development of an accurate full-dimensional potential energy surface for HCNO, we address here several aspects of the $a b$ initio treatment relevant from the computational point of view. An appropriate choice of one-electron basis functions and correlation method(s) is required to minimize the necessarily expensive electronic structure computations for several thousands of geometrical arrangements entering the construction of a full dimensional analytical representation.

The results presented in the preceeding sections have shown the importance of core correlation for the accurate description of all three CHNO isomers. The explicit inclusion of core electrons in correlated electronic structure calculations significantly increases the computational cost due to a larger one-electron basis set and a much larger number of many-electron configurations. For the basis sets of quadruple $\zeta$ quality, the number of primitive (contracted) Gaussian-type orbitals for the CHNO isomers is 286 (195) and 388 (282) for cc-pVQZ and cc-pCVQZ, respectively. The number of singly and doubly external configuration state functions (CSFs) in $C_{s}$ symmetry increases from 552481 and 1199875 for cc-pVQZ and cc-pCVQZ to 1054561 and 2293741 for cc-pVQZ(all) and cc-pCVQZ(all), respectively.

Single-point CCSD $(\mathrm{T}) / \mathrm{cc}-\mathrm{pVQZ}$ calculations in the frozen-core approximation take approximately 150, 500, and $1450 \mathrm{~s}$ for linear, planar, and general arrangements on a $2 \mathrm{GHz}$ clock rate dual-core computer and all-electron calculations with cc-pVQZ(all) approximately double the execution times. Replacement of the cc-pVQZ(all) treatment by a cc-pCVQZ(all) treatment increases the timing for a single-point all-electron $\operatorname{CCSD}(\mathrm{T})$ calculation by a factor of ca. 4 to 1400, 4000, and $12000 \mathrm{~s}$ for a linear, 
TABLE VII: Harmonic wavenumbers (in $\mathrm{cm}^{-1}$ ) of HCNO, HNCO, and HOCN, computed at the optimized geometries reported in Tables I, II, and III. For ease of visualization, we abbreviate with VXZ the basis set cc-pVXZ. The symmetry labels of the $C_{s}$ point group are used here.

\begin{tabular}{|c|c|c|c|c|c|c|c|c|c|}
\hline $\mathrm{HCNO}$ & VDZ & VTZ & VQZ & $\begin{array}{r}\text { VQZ } \\
\text { linear }\end{array}$ & VDZ(all) & VTZ(all) & VQZ(all) & $\begin{array}{r}\text { VQZ(all) } \\
\text { linear }\end{array}$ & normal mode \\
\hline $\begin{array}{l}\omega_{1}\left(\mathrm{a}^{\prime}\right) \\
\omega_{2}\left(\mathrm{a}^{\prime}\right) \\
\omega_{3}\left(\mathrm{a}^{\prime}\right) \\
\omega_{4}\left(\mathrm{a}^{\prime}\right) \\
\omega_{5}\left(\mathrm{a}^{\prime}\right) \\
\omega_{6}\left(\mathrm{a}^{\prime \prime}\right)\end{array}$ & $\begin{array}{r}3426 \\
2217 \\
1288 \\
542 \\
459 \\
545\end{array}$ & $\begin{array}{r}3467 \\
2250 \\
1274 \\
553 \\
301 \\
554\end{array}$ & $\begin{array}{r}3479 \\
2267 \\
1273 \\
554 \\
194 \\
554\end{array}$ & $\begin{array}{r}3493 \\
2280 \\
1269 \\
555,555 \\
128 \imath, 128 \imath\end{array}$ & $\begin{array}{r}3434 \\
2223 \\
1290 \\
544 \\
454 \\
547\end{array}$ & $\begin{array}{r}3486 \\
2273 \\
1287 \\
566 \\
299 \\
567\end{array}$ & $\begin{array}{r}3504 \\
2295 \\
1279 \\
565 \\
85 \\
565\end{array}$ & $\begin{array}{r}3505 \\
2296 \\
1279 \\
565,565 \\
33,33\end{array}$ & $\begin{array}{l}\text { C-H stretch } \\
\text { C-N-O as.stretch } \\
\text { C-N-O s.stretch } \\
\text { C-N-O bend } \\
\text { H-C-N bend } \\
\text { torsion }\end{array}$ \\
\hline HNCOI & VDZ & VTZ & VQZ & | & VDZ(all) & VTZ(all) & VQZ(all) & & normal mode \\
\hline $\begin{array}{l}\omega_{1}\left(\mathrm{a}^{\prime}\right) \\
\omega_{2}\left(\mathrm{a}^{\prime}\right) \\
\omega_{3}\left(\mathrm{a}^{\prime}\right) \\
\omega_{4}\left(\mathrm{a}^{\prime}\right) \\
\omega_{5}\left(\mathrm{a}^{\prime}\right) \\
\omega_{6}\left(\mathrm{a}^{\prime \prime}\right)\end{array}$ & $\begin{array}{r}3660 \\
2299 \\
1292 \\
855 \\
547 \\
609\end{array}$ & $\begin{array}{r}3688 \\
2307 \\
1304 \\
825 \\
562 \\
625\end{array}$ & $\begin{array}{r}3693 \\
2307 \\
1311 \\
818 \\
567 \\
631\end{array}$ & & $\begin{array}{r}3667 \\
2304 \\
1295 \\
854 \\
549 \\
610\end{array}$ & $\begin{array}{r}3713 \\
2329 \\
1319 \\
809 \\
566 \\
633\end{array}$ & $\begin{array}{r}3711 \\
2324 \\
1321 \\
805 \\
568 \\
634\end{array}$ & & $\begin{array}{l}\text { N-H stretch } \\
\text { N-C-O as.stretch } \\
\text { N-C-O s.stretch } \\
\text { H-N-C bend } \\
\text { N-C-O bend } \\
\text { torsion }\end{array}$ \\
\hline $\mathrm{HOCN}$ & VDZ & VTZ & VQZ & & VDZ(all) & VTZ(all) & VQZ(all) & & normal mode \\
\hline $\begin{array}{l}\omega_{1}\left(\mathrm{a}^{\prime}\right) \\
\omega_{2}\left(\mathrm{a}^{\prime}\right) \\
\omega_{3}\left(\mathrm{a}^{\prime}\right) \\
\omega_{4}\left(\mathrm{a}^{\prime}\right) \\
\omega_{5}\left(\mathrm{a}^{\prime}\right) \\
\omega_{6}\left(\mathrm{a}^{\prime \prime}\right)\end{array}$ & $\begin{array}{r}3793 \\
2305 \\
1288 \\
1063 \\
407 \\
462\end{array}$ & $\begin{array}{r}3805 \\
2320 \\
1275 \\
1074 \\
427 \\
484\end{array}$ & $\begin{array}{r}3809 \\
2325 \\
1270 \\
1079 \\
432 \\
489\end{array}$ & & $\begin{array}{r}3796 \\
2309 \\
1288 \\
1066 \\
409 \\
464\end{array}$ & $\begin{array}{r}3823 \\
2341 \\
1269 \\
1086 \\
431 \\
497\end{array}$ & $\begin{array}{r}3817 \\
2338 \\
1273 \\
1086 \\
435 \\
494\end{array}$ & & $\begin{array}{l}\mathrm{H}-\mathrm{O} \text { stretch } \\
\text { C-N stretch } \\
\mathrm{H}-\mathrm{O}-\mathrm{C} \text { bend } \\
\mathrm{C}-\mathrm{O} \text { stretch } \\
\text { O-C-N bend } \\
\text { torsion }\end{array}$ \\
\hline
\end{tabular}

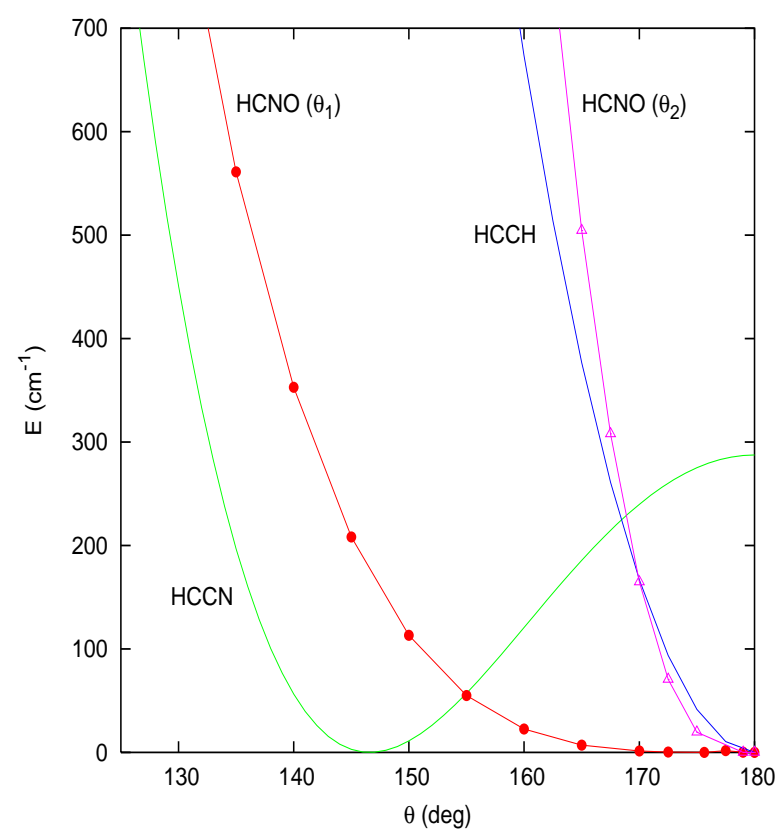

FIG. 6: Minimum energy paths along the bending angle for the HCNO, HCCN, and HCCH molecules. The angle HXY denotes the $\mathrm{HCN}$ angle $\theta_{1}$ of $\mathrm{HCNO}$ and the $\mathrm{HCC}$ angle of $\mathrm{HCCN}$ and $\mathrm{HCCH}$, respectively. An additional profile is shown for the CNO angle $\theta_{2}$ in HCNO. For more details, see the text. planar, and spatial geometry, respectively. CCSD(T)/ccpV5Z computations in the frozen-core approximation took approximately 1350, 3500, and $11000 \mathrm{~s}$, largely excluding a basis set of quintuple $\zeta$ quality for the scanning of the PES in the computationally even more expensive all-electron approach.

Since the cc-pCVXZ basis set family is specifically designed for core-core and core-valence correlation, we also tested the performance of cc-pCVQZ in combination with the frozen-core approximation. These calculations yielded an equilibrium structure of [2.0060 $\mathrm{a}_{0}, 2.2009 \mathrm{a}_{0}$, $2.2721 \mathrm{a}_{0}, 164.91^{\circ}, 176.53^{\circ}$ ] at an energy of -168.375308 $E_{h}$ for planar HCNO and of [2.0042 $\mathrm{a}_{0}, 2.1956 \mathrm{a}_{0}, 2.2748$ $\left.\mathrm{a}_{0}, 180.0^{\circ}, 180.0^{\circ}\right]$ at an energy of $-168.375271 E_{h}$ for linear HCNO, yielding a barrier to linearity of $6.70 \mathrm{~cm}^{-1}$. Due to the striking similarity of these results with the cc-pVQZ values from Table I, we have not pursued further the cc-pCVXZ calculations with valence correlations only.

Two basis sets emerge from our current study as candidates for the development of the full PES, namely ccpVQZ(all) and cc-pCVQZ(all). Inspection of Tables I, II, and III, together with Figs. 1 and 3, clearly shows a more balanced performance for cc-pCVXZ(all), accompanied with a monotonic convergence behaviour for the quantities studied here. In view of much higher $\mathrm{CPU}$ requirements of the cc-pCVQZ calculation, we however consider developing a PES based only on the cc-pVQZ(all) points. This cc-pVQZ(all) PES may subsequently be im- 
TABLE VIII: RHF barrier to linearity and correlation energy contribution to the $\operatorname{CCSD}(\mathrm{T})$ barrier to linearity obtained for HCNO at the optimized cc-pV6Z, cc-pV5Z(all), and ccpCV5Z(all) geometries (first three rows) and the optimized frozen core cc-pV5Z geometry denoted here by geo5 (last five rows). The latter series of calculations, cc-pVXZ(geo5), is carried out at the geometry geo5 with the cc-pVXZ basis set for $X=2-6$. The optimized geometries are taken from Table I. All quantities are given in $\mathrm{cm}^{-1}$. For more details, see the text.

\begin{tabular}{lrr}
\hline \hline & RHF & $\begin{array}{r}\text { Correlation } \\
\text { contribution }\end{array}$ \\
\hline cc-pV6Z & -123.6 & 123.3 \\
cc-pV5Z(all) & -20.3 & 19.9 \\
cc-pCV5Z(all) & -70.0 & 69.1 \\
\hline cc-pVDZ(geo5) & -163.5 & 219.7 \\
cc-pVTZ(geo5) & -182.5 & 201.7 \\
cc-pVQZ(geo5) & -185.7 & 191.5 \\
cc-pV5Z(geo5) & -186.7 & 187.6 \\
cc-pV6Z(geo5) & -186.7 & 185.4 \\
\hline \hline
\end{tabular}

proved through a fractional inclusion of higher quality cc-pCVQZ(all) points or alternatively adjusted to reproduce selected experimental data, as previously done in the study on $\mathrm{HCCN}^{27}$.

\section{CONCLUSION}

Rovibrational calculations with exact hamiltonians require reliable potential energy surfaces covering large regions of configuration space. Checking the convergence of available electronic structure methods is a mandatory initial step for the identification of a strategy which combines sufficient accuracy with acceptable computational cost. Our systematic investigation of the impact of basis set size and level of correlation treatment have confirmed the previously observed difficulties to arrive at a converged equilibrium geometry for the HCNO molecule whose rovibrational spectrum is particularly rich and complicated. We believe, however, to have shown beyond reasonable doubt that HCNO is indeed linear at electronic equilibrium. The inclusion of core correlation and high angular momentum basis functions proved to be essential to arrive at this result. Similar, but less pronounced, effects of core correlation were found for the isomers HNCO and HOCN, the most notable being a surprising sensitivity of the barrier to linearity. It remains an open question if the difficulty of converging to the linear arrangement reflects merely the intrinsic physics of the HCNO molecule or some subtle symmetry breaking effects in the electronic structure methodology.

To demonstrate and rationalize the difficulties encountered in the present study, we finally summarize in Table VIII the RHF barriers to linearity for HCNO, obtained at several selected $\operatorname{CCSD}(\mathrm{T})$ geometries. The barrier $\mathrm{E}_{b a r}$ to linearity is calculated as common, $\mathrm{E}_{b a r}=\mathrm{E}_{l i n^{-}}$ $\mathrm{E}_{\text {min }}$, such that a negative $\mathrm{E}_{b a r}$ corresponds to a situation of a more stable linear configuration (lin). In the correlation treatment, the zero-order RHF solution is improved by adding the correlation energy contribution. The CCSD $(\mathrm{T})$ correlation contribution to $\mathrm{E}_{b a r}$ increases the barrier to linearity of $\mathrm{HCNO}$, i.e. it favours its nonlinear coplanar arrangement, as seen in Table VIII. The final $\operatorname{CCSD}(\mathrm{T})$ result for $\mathrm{E}_{b a r}$ appears to be the result of a very subtle interplay between the two energy parts, the dominant RHF energy and the small correlation energy contribution, whose effects on $\mathrm{E}_{b a r}$ are varying in the opposite sense.

The analysis of minimum energy paths on the HCNO surface indicates an extreme flatness of the surface upon bending and the presence of strong angular-radial coupling. The latter effect can easily lead to the appearance of an adiabatic barrier at the linear arrangement, such that the molecule effectively behaves as slightly non-linear, as previously proposed by Bunker et al. ${ }^{10}$. A distinct advantage of progressive subspace diagonalisation and truncation discrete variable approaches ${ }^{46,47}$ over alternative techniques ${ }^{48}$ is the possibility to visualise the dynamics of large amplitude motions through the construction of effective adiabatic potentials for low frequency modes at given excitations of other vibrational modes. The application of this type of analysis to the potential energy surface and rovibrational dynamics of the quasi-linear molecule HCCN indicated very strong variations of the effective barrier to linearity upon excitation of stretching modes. ${ }^{27}$ The structure of the minimum energy paths on the HCNO surface lets us expect similar coupling effects between high and low frequency modes.

\section{Acknowledgments}

Both authors have enjoyed the privilege of working in the theoretical chemistry group of S. D. Peyerimhoff at the University of Bonn in their very early career, albeit without meeting each other there. The friendly and exciting atmosphere and the possibility of contributing to advanced research projects as an undergraduate student left an unforgettable mark on ML and laid the foundation for a successful return into theory after fruitful years spent with experimental work.

\footnotetext{
* Corresponding author; Electronic address: mladenov@ univ-mlv.fr
}

$\dagger$ Electronic address: lewerenz@univ-mlv.fr

1 W. R. Thorson and I. Nakagawa, J. Chem. Phys. 33 (1960) 
994.

2 B. P. Winnewisser, In K. Narahari Rao, editor, Molecular Spectroscopy: Modern Research volume 3. Academic Press Orlando 1985.

3 M. Winnewisser, B. P. Winnewisser, I. R. Medvedev, F. C. De Lucia, S. C. Ross and L. M. Bates, J. Mol. Struct. 798 (2006) 1.

4 B. P. Winnewisser, M. Winnewisser and F. Winther, J. Mol. Spectrosc. 51 (1974) 65.

${ }^{5}$ E. L. Ferretti and K. Narahari Rao, J. Mol. Spectrosc. 51 (1974) 97.

${ }^{6}$ K. Yamada, B. P. Winnewisser and M. Winnewisser, J. Mol. Spectrosc. 56 (1975) 449.

7 B. P. Winnewisser and P. Jensen, J. Mol. Spectrosc. 101 (1983) 408.

8 S. Albert, M. Winnewisser and B. P. Winnewisser, Ber. Bunsenges. 100 (1996) 1876.

9 S. Albert, K. K. Albert, M. Winnewisser and B. P. Winnewisser, J. Mol. Spectrosc. 599 (2001) 347.

10 P. R. Bunker, B. M. Landsberg and B. P. Winnewisser, J. Mol. Spectrosc. 74 (1979) 9.

11 M. T. Nguyen, K. Pierloot and L. G. Vanquickenborne, Mol. Phys. 78 (1993) 319.

12 A. P. Rendell, T. J. Lee and R. Lindh, Chem. Phys. Lett. 194 (1992) 84.

13 N. Pinnavaia, M. J. Bramley, M.-D. Su, W. H. Green and N. C. Handy, Mol. Phys. 78 (1993) 319.

14 J. Koput, B. P. Winnewisser and M. Winnewisser, Chem. Phys. Lett. 255 (1996) 357.

15 A. M. Mebel, A. Luna, M. C. Lin and K. Morokuma, J. Chem. Phys. 105 (1996) 6439.

16 M. S. Schuurman, S. R. Muir, W. D. Allen and H. F. Schaefer III, J. Chem. Phys. 120 (2004) 11586.

17 D. C. McKean, J. L. Duncan and L. Batt, Spectrochim. Acta 29A (1973) 1037.

18 A. L. L. East, C. S Johnson and W. D. Allen, J. Chem. Phys. 98 (1993) 1299.

19 D. Poppinger, L. Radom and J. A. Pople, J. Am. Chem. Soc. 99 (1977) 7806.

20 J. H. Teles, G. Maier, B. A. Hess, Jr., L. J. Schaad, M. Winnewisser and B. P. Winnewisser, Chem. Ber. 122 (1989) 753.

21 J.-A. Miller and C. T. Bowman, Int. J. Chem. Kin. 23 (1991) 289.

22 R. Homma and J.-Y. Chen, J. Mol. Spectrosc. 123 (2001) 303.

23 J.-Y. Park and D. E. Woon, ApJ 601 (2004) L63.

24 M. Niedenhoff, K. M. T. Yamada, M. Winnewisser and S. C. Ross, J. Mol. Struct. 352 (1995) 423.

25 M. E. Jacox and D. E. Milligan, J. Chem. Phys. 40 (1964) 2457.
${ }^{26}$ R. N. Dixon, Trans. Far. Soc 60 (1964) 1363.

27 M. Mladenović, P. Botschwina and C. Puzzarini, J. Phys. Chem. 110 (2006) 5520.

28 M. Mladenović, J. Chem. Phys. 112 (2000) 1070.

29 T. H. Dunning, Jr., J. Chem. Phys. 90 (1989) 1007.

30 D. E. Woon and T. H. Dunning, Jr., J. Chem. Phys. 103 (1995) 4572.

31 MOLPRO, version 2006.1, a package of ab initio programs, H.-J. Werner, P. J. Knowles, R. Lindh, F. R. Manby, M. Schütz, P. Celani, T. Korona, G. Rauhut, R. D. Amos, A. Bernhardsson, A. Berning, D. L. Cooper, M. J. O. Deegan, A. J. Dobbyn, F. Eckert, C. Hampel and G. Hetzer, A. W. Lloyd, S. J. McNicholas, W. Meyer and M. E. Mura, A. Nicklass, P. Palmieri, R. Pitzer, U. Schumann, H. Stoll, A. J. Stone, R. Tarroni and T. Thorsteinsson, see http://www.molpro.net.

32 C. Hampel, K. A. Peterson and H.-J. Werner, Chem. Phys. Lett. 190 (1992) 1, and references therein.

33 M. J. O. Deegan and P. J. Knowles, Chem. Phys. Lett. 227 (1994) 321.

${ }^{34}$ F. Eckert, P. Pulay and H.-J. Werner, Theor. Chem. Acc. 100 (1998) 21.

35 G. Rauhut, A. El Azhary, F. Eckert, U. Schumann and H.-J. Werner, Spectrochim. Acta, Part A 55 (1999) 651.

36 M. Rosenstock, P. Rosmus, E. A. Reinsch, O. Treutler, S. Carter and N. C. Handy, Mol. Phys. 93 (1998) 853.

37 T. J. Lee and P. R. Taylor, Int. J. Quant. Chem. Symp. 23 (1989) 199.

38 F. Jensen, Introduction to Computational Chemistry, (Wiley, New York, 2007), 2nd ed.

39 J. Demaison, L. Margulès and J. E. Boggs, Chem. Phys. 260 (2000) 65.

40 A. G. Császár, W. D. Allen and H. F. Schaefer III, J. Chem. Phys. 108 (1998) 9751.

41 G. Tarczay, A. G. Császár, W. Klopper and H. M. Quiney, Mol. Phys. 99 (2001) 1769.

42 I. Mills, T. Cvitaš, K. Homann, N. Kallay and K. Kuchitsu, Quantities, Units and Symbols in Physical Chemistry, Second Edition, (Blackwell Scientific Publications, Oxford, 1993).

43 I. M. Mills, J. Phys. Chem. 88 (1984) 532.

44 M. Mladenović and M. Lewerenz, Chem. Phys. Lett. 321 (2000) 135.

45 G. Strey and I. M. Mills, J. Mol. Spectrosc. 59 (1976) 103.

46 Z. Bačić and J. C. Light, Annu. Rev. Phys. Chem. 40 (1989) 469.

47 M. Mladenović, Spectrochim. Acta, Part A 58 (2002) 795.

48 J. Light and T. Carrington, Jr., Adv. Chem. Phys. 114 (2000) 263. 